\title{
Multinacionais do Direito, escritórios de advocacia e pro bono: elementos para uma análise comparativa dos campos jurídicos francês e americano
}

\author{
Multinationals of Law, law and pro bono offices: elements for a \\ comparative analysis of the French and American legal \\ fields
}

\section{Charles Bosvieux-Onyekwelu}

\section{Resumo}

A partir da comparaçáo dos Estados Unidos e da França, o artigo problematiza a natureza nacional do campo jurídico tendo como foco a advocacia pro bono nas multinacionais do Direito e nos escritórios de advocacia franceses. Nessa perspectiva, se pergunta quais as condiçóes em que práticas e normas jurídicas podem ser transplantadas de um país para outro (legal tranplant). A pesquisa realizada iniciou por uma série de entrevistas com advogados deste setor e com a observação direta de interaçóes entre prestadores e destinatários das atividades pro bono. As primeiras conclusóes indicam que a maioria dos escritórios franceses não têm meios humanos e financeiros para institucionalizar o pro bono com a amplitude de um verdadeiro dispositivo de ação pública.

\section{Palavras-chave}

Pro bono; Advogados; Multinacionais do Direito; Mundialização.

\begin{abstract}
Through a comparison of the United States and France, this article analyses the national nature of the juridical field with a focus on pro bono juridical work in multinational law firms and in French law offices. In this perspective, it is concerned with the legal conditions in which law practices and norms can be transplanted from one country to the other (legal transplant). The research initiated with a series of interviews with law professionals in the sector and with the direct observation of interactions between suppliers and receivers of pro bono activities. The first conclusions indicate that most French law offices do not possess the human and financial means to institutionalize pro bono work with the amplitude of a real public action instrument.
\end{abstract}

\section{Keywords}

Pro Bono; Lawyers; Multinational Law Firms; Mundialization. 
34 | Charles Bosvieux-Onyekwelu

\section{Introdução ${ }^{1}$}

Importada dos Estados Unidos, a prática da advocacia pro bono tornou-se na França, depois de quinze anos, um fenômeno recorrente. Esta afirmou-se, ao mesmo tempo, como expressão de um ethos do serviço público e como um recurso para melhorar a reputação profissional dos advogados. Essa prática acompanha o desenvolvimento dos escritórios de advocacia e, muitas vezes, entra em conflito com a estrutura dos mesmos. O caso francês é exemplar nesse sentido. Na França predomina um modelo organizacional onde um número de significativo de advogados atua em escritórios pequenos, com no máximo dez sócios que reivindicam sua "independência". São organizaçôes muito menores do que as imensas sociedades de advogados multinacionais que se expandem a partir dos Estados Unidos (BESSY, 2015).

A pesquisa que originou esse artigo parte da constatação de que os trabalhos nas Ciências Sociais que analisam movimentos amplos como o New Public Management (NPM) se interessaram predominantemente pelos efeitos do mundo privado sobre o setor público. Nesses termos, outros fenômenos não foram enfatizados, tais quais os efeitos que possam advir do sentido contrário, ou mesmo, na maneira como certos atores privados podem se posicionar enquanto produtores de políticas públicas. Conforme acentuam France e Vauchez (2011, p. 11) "enfatizando a reforma gerencial do setor público, frequentemente renunciamos explorar as transformações em muitos aspectos simétrica, que dizem respeito aos atores econômicos privados na redefinição neoliberal do Estado". Nesse sentido, a prática do pro bono é heurística, pois ela sugere que não se considerem os advogados de negócios somente pela expertise técnica que eles mobilizam na gestão dos processos, "mas também pela multiplicidade dos papéis e relações sociais que eles têm condições de entabular e manter sucessivamente ou simultaneamente" (VAUCHEZ, 2012, p. 41). A comparação entre França e Estados Unidos traz elementos importantes para a compreensão das lutas de definição que podem resultar da fricção entre duas visões da "profissão" que são muito diferentes. Conforme Simeant (2015), a perspectiva comparativa convida a considerar a competição internacional pelo "universal" como produto de estratégias de internacionalizaçáo concorrentes de diversos segmentos de

\footnotetext{
1 Tradução realizada por Fabiano Engelmann a partir do texto "Le pro bono des multinationales du droit et des cabinets d'avocat-e-s: un instrument de comparaison entre les champs juridiques français et états-uniens" apresentado no Colóquio Réceptions et usages de la sociologie d’Yves Dezalay realizado na Un. Paris 1 Sorbonne em janeiro 2018.
} 
elites nacionais, e de diferentes tipos de elites profissionais. Nesse sentido, se trata de considerar o mundo jurídico norte americano como constituindo "a base da nova forma de universalização de um campo jurídico” (DEZALAY, 2015, p. 49). Analisados do ponto de vista da sociologia da ação pública, os serviços jurídicos prestados gratuitamente pelos escritórios de advocacia originam-se de uma integração da doação de tempo de trabalho dos colaboradores, mas também e, sobretudo, de um circuito de restituição paralela do imposto gerido por operadores privados. Esses serviços públicos "terceirizados" aparecem como efeitos induzidos do NPM sob a forma de uma hibridização regressiva, "os governos sendo incapazes de monopolizar, ou mesmo concentrar a prestação de serviços" (SAVAS, 2000, p. 1736). Ele revela a passagem da Sociologia do Estado para uma Sociologia da Ação Pública menos estado-centrista (HASSENTEUFEL, 2011) que a análise clássica de Políticas Públicas.

No meio das multinacionais do direito, o pro bono é, em efeito, organizado como uma verdadeira policy. Ou seja, como um programa de açóes perseguido de maneira coerente por uma entidade coletiva. O especialista na questão Scott Cummings refere a existência de uma "institucionalização do pro bono" (CUMMINGS, 2009, p. 338), com políticas implicando um organograma e um enquadramento mundial. Tal como uma evolução das law firms, reunindo na sua prática o "serviço público" e o "serviço do capital" (DEZALAY, 1992), se insere em uma nova retórica da legitimação do capitalismo fundado sobre o tema da empresa cidadã e socialmente responsável. Ela tende, pois, a direcionar a NPM mais para a retirada do Estado que para a reforma das administrações públicas.

Os serviços jurídicos prestados gratuitamente pelos profissionais do Direito remontam a uma tradição antiga de caridade para os pobres e necessitados - pode-se remontar às consultas caritativas, descritas com precisão na obra de Lucien Karpik (1995). O pro bono reconecta, assim, os advogados com as características de uma profissão perpassada por uma longa tradição de ethos de devotamento convocada, nos últimos anos, a redefinir sua vocação pública. Em termos de politização, esta "advocacia de causas" é mais orientada pela filantropia do que por um projeto global de transformação social. De fato, o que determina o mercado do pro bono não é a demanda do público, mas os interesses e prioridades daqueles que alocam recursos via pro bono. São as law firms que impóem sua própria agenda com seus destinatários (ONG e associações bem mais do que os indivíduos) escolhidos a dedo por triagem, assim como as causas (os incapacitados, o acesso a educação, os migrantes), 
cuidadosamente escolhidas por seu maior consenso, fator que evita confrontos sociais. Sobretudo é necessário que a temática escolhida não seja suscetível de afetar os interesses dos grandes grupos de escritórios de advocacia especializados em "direito empresarial" que continua sendo obviamente, a atividade mais lucrativa e que lhes dá condições de financiar sua política pro bono.

Partindo das questões esboçadas, esta contribuição se funda sobre dois elementos centrais para a pesquisa. Primeiramente, a ideia de que é importante ter em conta a influência do setor privado sobre o setor público e, assim, verificar os efeitos da NPM nas profissóes, do ponto de vista da terceirização dos serviços públicos. Segundo a convicção de que é preciso levar a sério a passagem da sociologia das políticas públicas para uma sociologia da ação pública e, pois, admitir que os operadores privados possam produzir políticas públicas. Desta forma, o pro bono é analisado como um dispositivo de ação pública, e os advogados tratados como uma população privilegiada para a análise. Esse grupo tem e de longa data, dois inimigos principais: o mercado e o poder político, razão pela qual é particularmente interessante de observar as transformaçóes que a NPM impacta no mundo do trabalho dos advogados. O pro bono é, em um primeiro momento, apreendido como uma forma de desestatização do serviço público da justiça. Em um segundo momento, explicitamos a forma como as law firms escolhem os destinatários de seus serviços jurídicos tentando elucidar as motivaçóes dos advogados pro bono.

\section{Métodos e fontes de pesquisa}

A base desse trabalho é uma pesquisa em andamento realizada no quadro de um pós-doutorado na École des Hautés Études en Sciences Sociales-EHESS. Trata-se essencialmente de uma exploração preliminar, iniciada como parte do desenvolvimento de um projeto de pesquisa do Conseil Nationale de Recherche Scientifiique - CNRS em dezembro de 2016. Após uma revisão da literatura disponível sobre o assunto (já consistente em inglês, quase inexistente em francês), a parte empírica da pesquisa começou em setembro de 2017. Como ilustra este artigo, a pesquisa combina uma perspectiva da Sociologia do Direito, da Sociologia do Trabalho, das Profissóes e da Sociologia Política do Capitalismo. Seu objetivo é mapear o setor pro bono, identificando todos os atores relevantes: advogados, representantes da ordem dos advogados, líderes de associaçôes, ONGs e organizaçôes internacionais, sem esquecer os profissionais envolvidos das clearing houses. Mobiliza uma abordagem multi-métodos combinando entrevistas, observaçôes e questionários 
(um para advogados pro bono e outro para os destinatários). São privilegiados dois escritórios de advocacia internacionais com sede em Paris. Essas duas sociedades foram escolhidas por motivos de oportunidade, foi onde o pesquisador tem contatos, mas também porque há escritórios em Paris e, acima de tudo, porque fazem parte dos escritórios pioneiros em pro bono. A estrutura internacional do primeiro escritório analisado, por exemplo, emprega 25 funcionários em tempo integral para sua política pro bono, sem contar os efetivos da firma nos Estados Unidos (as duas entidades são distintas). Além desses dois escritórios, foram realizados contatos - de maneira mais informal - com outras duas global law firms.

O recurso à observação etnográfica tem por objetivo a melhor compreensão da natureza das interaçóes que resultam da prática do pro bono. Por sua capacidade de acesso à complexidade do mundo social, a etnografia é um instrumento privilegiado para estudar a diversidade dos membros da prestação de serviço para "apreender as zonas da atividade onde os assalariados indagam a questão da legitimidade do que fazem” (AVRIL, CARTIER e SERRE, 2010, p. 49) e para situar onde são afetados positiva ou negativamente, pelo fato de prestar um serviço gratuito. Nesse sentido, trata-se de descrever de maneira concreta as relaçóes de prestação e de recepção de atividades pro bono dos advogados para os destinatários da ajuda desde as reuniões nas quais são negociadas as colaborações entre diferentes atores e se desenham os contornos dos projetos lançados no quadro do pro bono.

Observo, assim, as interações entre os gerentes pro bono e os responsáveis pelas associações ou clearing houses. Esta parte da pesquisa requer uma constante negociação com os escritórios, a qual se faz caso a caso em função da natureza mais ou menos confidencial do dossiê em questão. A dimensão empírica da pesquisa se soma à exploração de arquivos em uma perspectiva genealógica. Em especial, os da Ordem dos advogados norte-americanos), dentre os quais tenho por foco as seçôes da Divisão de Serviços Legais e da Divisão dos Serviços Públicos, assim como, os da Associação das liberdades civis norte-americana, uma das principais, associações com fins nãolucrativos dos Estados Unidos. Também foi incluído o arquivo da Fundação Ford. Este mergulho nos arquivos é acompanhado por um grande trabalho de recuperação da documentação existente dentro dos escritórios e da imprensa jurídica especializada. O pro bono é, de fato, um setor que produz muitos documentos oficiais, "literatura cinza”, tais como, relatórios de atividades, relatórios anuais, folhetos, organogramas, rankings e gráficos. 


\section{A difusão de uma prática de origem americana em um contexto de globalização dos serviços jurídicos}

Seja na França ou nas naçóes de common law, a cultura profissional dos advogados é orientada para a representação de interesses públicos: "eles se apresentam como os arautos da liberdade e das ideias generosas", cultivam o desinteresse destinado a ganhar a confiança do público (ASSIER-ANDRIEU, 2011, p. 26). Em alguns contextos sócio históricos, os advogados aparecem assim como o equivalente funcional dos intelectuais. É o que mostram os trabalhos sobre os cause lawyering (ISRAËL, 2009; McCANN, 2004; SARAT e SCHEINGOLD, 1998, 2004 e 2006). Entre 1959 e 1978, a fundação Ford destinou 13 milhôes de dólares de subvenções a uma centena de faculdades de direito visando a criação de serviços de assistência jurídica aos mais pobres (JOY, 2003).

Os motivos que impulsionam os profissionais do direito a agir gratuitamente são múltiplos. Eles podem participar da construção do capitalismo com rosto humanizado tendo por finalidade, como no caso das law firms, de modificar a desconfiança popular que marca a profissão de advogado principalmente nos Estados Unidos, à imagem de advogado ganancioso. Nesse contexto, podemos notar que o pro bono dos profissionais do direito se desenvolve no contexto da expansão do setor empresarial (DEZALAY, 1992; DEZALAY e GARTH, 2004). Temos assim constituído um mercado das causas, comparável às fundações criadas por grandes grupos internacionais para aumentar sua respeitabilidade e transformar seu capital econômico em capital social e simbólico. Esse fenômeno aproxima-se do que a sociologia do humanitarismo descreve como uma militância de boa consciência (COLLOVALD et al., 2002), pelo qual certas elites procuram "atestados de desinteresse" (WILLEMEZ, 2002, p. 49 e 64).

É difícil de definir de forma monovalente e homogênea a noção de pro bono (encurtamento da expressão latina pro bono publico, para o bem público), salvo para remeter, como fazem certos advogados franceses, para a pura e simples não-cobrança de consultoria jurídica. De certa forma, a definição da prática é um dos objetos da pesquisa. Pode-se afirmar, preliminarmente, que o fenômeno está ligado em parte ao serviço público da justiça. Não é trivial observar que no sintagma do serviço público (que originalmente, se aplicava em francês aos eclesiásticos), a expressão pro bono se impôs na linguagem jurídica atual em detrimento da mais antiga e eivada de religiosidade, pro deo.

Nos Estados Unidos e no mundo anglófono, mesmo que a expressão se incorporou à língua corrente para designar algo que se faz de maneira desinteressada, 
ela se vincula especificamente a uma forma de trabalho bem particular no quadro de uma organização complexa e própria às law firms. A originalidade do modelo de pro bono exportado dos Estados Unidos repousa de fato sobre uma cobrança por hora, o que leva ao questionamento da eficiência do trabalho. Contando cada minuto despendido com um processo, os empregados dos escritórios são remunerados por meio de uma contagem anual fixa paga em 12 vezes. Eles têm geralmente um objetivo de atingir 8000 horas. Concretamente, esse tipo de advogado tem a sua disposição um software dedicado a contar as horas trabalhadas, chamado Smart Timer, que lhe permite registrar seus horários no sistema sem se preocupar com o pagamento do cliente. $\mathrm{O}$ trabalho em processos pro bono entra nessas horas que podem ser cobradas, sob a forma de um fee credit atribuído ao funcionário responsável por um processo. Claramente, o escritório remunera seu "assalariado" por um trabalho efetuado, mas não cobra nada da ONG ou associação beneficiada. Trata-se, pois, de uma forma de doação integrada ao tempo de trabalho.

$\mathrm{Na}$ França, a implantação do pro bono demorou mais tempo em razão notadamente da cobrança por hora que ela pressupóe. Foi no final da década de 1980 que alguns escritórios de advocacia anglo-americanos se instalaram em Paris e fizeram da França a capital europeia do direito continental. Nesse contexto, e por importação das law firms, que o termo pro bono apareceu na França e que a prática se expandiu. Esta prática pode também ser estudada como o que os juristas denominam, em direito comparado de legal transplant ${ }^{2}$. Nesse contexto, é importante observar que os advogados franceses têm uma utilização específica do termo. A Ordem dos Advogados de Paris, por exemplo, que por meio do fundo Paris Barreau Solidarité, serve igualmente de parceira, organiza eventos voltados para a promoção do pro bono.

Nos últimos anos, o pro bono se espalhou na França: o grupo bancário BNP Paribas recentemente iniciou um programa de desenvolvimento desse tipo, e, em 2011, iniciou o Pro Bono Lab organismo com fins lucrativos destinado a ligar doadores e associações que buscam profissionalizar sua atividade social. Evitando um uso normativo da noção e também sem decretar que a definição americana é necessariamente a melhor, podemos, todavia, considerar que o pro bono se distingue

\footnotetext{
${ }^{2} \mathrm{O}$ termo está entre aspas, porque os advogados que trabalham em escritórios de advocacia não têm o status de empregado (com a proteção que, do ponto de vista do direito do trabalho, deriva disso). Sobre a noção de "transplante legal", ver Bonichot e Morand-Deviller (2010); Gaudemet (1996) e Watson, (1974).
} 
da ação humanitária pura, ou seja, da participação benevolente em missôes associativas ou açóes filantrópicas. Mesmo que ela seja organizada por muitos atores no interior da economia social e solidária, ou por ações de associaçôes por meio de donativos, não se tratam de atividades jurídicas; "o que constitui a essência do pro bono" (DIENER, 2015, p. 142).

O desenvolvimento de atividades pro bono se insere no contexto de uma globalizaçáo crescente do campo jurídico que representa claramente um desafio para os diferentes profissionais do Direito. Uma Sociologia desse tipo de atividade deve ser comparativa, por exemplo, entre a ajuda jurisdicional francesa e a célebre decisão judicial da Corte Suprema Gideon versus Wainwright (1963) que evoca a sexta emenda da Constituição americana para afirmar the right to legal counsel. Esta comparação é necessária não somente pelo que ela significa sobre a posição dos poderes públicos no que concerne à garantia do acesso à justiça, mas também pelo que ela sugere sobre as relações entre o Estado e os profissionais do direito.

Em um certo número de países ocidentalizados proliferam nos últimos anos os escritórios de advocacia empresarial (corporate law firms) fundados sobre o modelo americano. Em seu estudo sobre as características do global lawyer a partir de uma pesquisa comparada na China e na Alemanha, Carole Silver afirma que entre 1988 e 2008, o número de escritórios estrangeiros das 250 maiores firmas americanas multiplicou-se por quatro e, no espaço de 20 anos, os advogados empregados nesses escritórios aumentaram em 12 vezes (SILVER, 2011). Essas law firms constituem modelos híbridos, maximizando as potencialidades do direito empresarial e criando um nicho para a assistência judiciária aos pobres. A maior parte das atividades desses escritórios se desenvolve fora da jurisdição: trata-se de assessorar seus clientes através dos meandros da regulação, de lhes representar frente às instâncias governamentais, de praticar lobby ou negociação. Ou seja, o essencial dos serviços que esta elite profissional fornece a seus clientes "não tem nada a ver com o direito" (GORDON, 1984, p. 70). Também, a "moda" do pro bono aparece como um sintoma do reforço da ética no Direito Empresarial.

\section{A falsa oposição entre culturas juridicas nacionais}

Uma das hipóteses de pesquisa, fortemente influenciada pelos trabalhos de Yves Dezalay, é que a exportação do pro bono na França pelas law firms não deve ser reduzida a uma oposição entre culturas jurídicas (common law x civil law). Mesmo que tentadora, a hipótese segundo a qual o baixo interesse dos advogados franceses 
pelo pro bono, tal como ele é organizado nas law firms, se explicaria por um motivo cultural de oposição dos sistemas jurídicos não se sustenta. Juristas e lawyers podem assim se unir na denúncia da assistência judiciária, pela qual os advogados acusam o Estado de fazer justiça social às suas custas e de "explorar, por sua própria conta, o capital simbólico dos advogados” (BOIGEOL, 1981, p. 84). Na França essa assistência é financiada ainda pelas "caixas de advogados", como é parcialmente nos Estados Unidos, a ajuda jurisdicional.

A oposição (se é que há oposição) deve ser analisada em termos de construção histórica dos campos jurídicos nacionais, assim como observa Dezalay (1992), quando lamenta a tradução da palavra "jurista" por "lawyer", que apaga, segundo ele, toda a oposição entre os juristas de Estado anglo-saxãos, "que são o produto da autonomização de campos jurídicos a margem do Estado -, ou mais precisamente a custa de uma construção burocrática do poder de Estado" (DEZALAY, 2013, p. 68). Uma via possível para a compreensão das divisões é a que opõe os tipos de capitais mobilizados (o capital econômico contra, ou antes, do capital cultural). É esta a orientação dos trabalhos de Dezalay(1992) sobre os mercadores de direito. Não tendo construindo ainda a análise de correspondência para descrever o espaço sobre o qual iniciou a pesquisa, atenho-me simplesmente a ideia de que os campos jurídicos francês e americano são determinados por seu passado respectivo, o que é visível no caso das suas relações diferenciadas com a atividade filantrópica.

\section{O pro bono como expressão das transformações contemporâ- neas do capitalismo}

Se a implantação do pro bono na França traz uma dimensão geopolítica dos sistemas jurídicos, esta última deve sobretudo permitir revelar as diferenças na relação com o capitalismo na França e na América do Norte. Dos dois lados não apenas, os sentidos da filantropia são diferentes; como a relação das profissões com o Estado é distinta. Assim, nos Estados Unidos, os lawyers não aceitam que o poder público possa regulamentar sua atividade. Isso os impede de agir paralelamente ao Estado, por exemplo, redistribuindo sua riqueza via pro bono. Mesmo na França, esse fator não é completamente ausente conforme aparece nas entrevistas realizadas: 
$\mathrm{Na}$ França, quando se fala em pro bono, isso nos remete a ajuda jurisdicional. Mas isso não tem nada a ver! Nossos programas pro bono são muito mais elaborados que as propostas de ajuda jurisdicional feitas pelo Estado, e os valores despendidos não são absolutamente iguais (entrevista número 3, sócio, homem, 58 anos).

A proposta desta pesquisa é ponderar com o fato de que em uma década, a ajuda jurisdicional quase dobrou, passando de 189 a 306 milhôes de euros entre 1998 e 2008. Em um contexto, marcado pelo desengajamento progressivo do Estado em matéria de serviço público e de solidariedade, os representantes da profissão não esquecem nunca do poderio público. Em 2009, o relatório Darrois preconizou, nesse espírito, certa racionalização da ajuda jurisdicional, defendendo o recrutamento, pelos escritórios, de advogados que seriam encarregados da gestão dos fundos públicos.

A difusão do pro bono se inscreve claramente na conjuntura de um capitalismo que emprega poderes públicos e experts que reivindicam a ética. Aplicado aos escritórios de advocacia, a responsabilidade social das empresas (RSE) compreende quatro elementos: a relação com o cliente, o funcionamento interno do escritório (entre outras as condições de trabalho e as possibilidades de formação), o ambiente e o pro bono. No concernente às relações externas, é patente que a prática desse último tem um impacto positivo sobre as relaçóes com os clientes. Tanto os que se beneficiam diretamente das atividades, quanto os clientes que pagam. Estes últimos muito sensíveis as atividades pro bono do seu advogado, por serem das grandes empresas e também, submetidos as regras da Responsabilidade Social Empresarial (SER).

Todo o mundo vai dizer que os escritórios de advocacia fazem o pro bono como uma marca. Mas concretamente, o que isso quer dizer ? Com o pro bono, a confiança entre cliente e advogado se acha reforçada. As condiçóes de trabalho melhoram e em alguns casos os clientes nos convidam para participar em um projeto pro bono deles (entrevistado número 7 , associado médio, homem, 33 anos).

Como demonstrado, essa insistência em um capitalismo empresarial responsável é contemporânea de um refluxo da intervenção do Estado na França e em outras democracias europeias há mais de trinta anos. No setor jurídico, esta evolução leva ao questionamento se as elites político-administrativas são ainda convencidas que 
a justiça de essência régia, e mais amplamente, as autoridades públicas desejam realmente que as instituiçóes filantrópicas desafiem o monopólio estatal do interesse geral (LAMBELET, 2012, p. 60).

Por outro lado, no sistema jurídico americano, ancorado em uma cultura fortemente libertária, o processo "substitui em parte as funções compensatórias do Estado-providência” (JASANOFF, 2013, p. 202). Mais ainda, nas altas esferas do direito empresarial, o recurso à prática da arbitragem acentua essa privatização da justiça, como indica Dezalay:

escolhendo seus árbitros, decidindo relativizar certas regras do
procedimento ou de substância, limitando a publicidade das decisóes, a
clientela da arbitragem não se concede somente uma justiça sob medida,
ela assegura também que os juízes que ela escolhe não farão prevalecer
uma lógica puramente jurídica sobre as preocupaçóes comerciais
inerentes a um conflito particular (DEZALAY, 1992, p. 214).

De forma mais geral, em Paris, onde se encontram 60\% dos advogados da França, quase a metade não tem praticamente nenhum contato com o Judiciário. Isso se aplica também às atividades pro bono, assunto sobre o qual os advogados entrevistados são unânimes: a regra, na França, é de limitar sua ação à consultoria.

O último elemento de análise suscetível de relacionar a propagaçáo do pro bono com as evoluçóes mais recentes do capitalismo contemporâneo diz respeito ao primado da objetividade das estatísticas, central na avaliação da performance (SALAIS, 2010). Em seu relatório anual sobre os serviços pro bono, o escritório Morrinson Foerster registra em torno de 97.000 horas efetuadas no ano de 2014. Esses balanços contábeis assinalam bem que a política do pro bono assume um viés de caridade ostentatória: os escritórios de advocacia querem anunciar o que realizam, pois o pro bono não comporta uma lógica de doação anônima.

Ao contrário, é um fator que entra em jogo no cálculo para a A-list, classificação publicada sobre as law firms pela The American Lawyer a partir de uma série de indicadores de performance e de qualidade. The American Lawyer, meio de referência para a informação jurídica nos Estados Unidos, criou um sistema de classificação específico para o pro bono (the Am. Law Pro Bono Scorecard) e o site vault.com, reconhecido pelas informaçóes corporativas seguiu essa tendência. Para acompanhar o movimento, a American Bar Association criou o Pro Bono 
Measurement Criteria Subcommittee encarregado de refletir sobre as formas de medir os benefícios trazidos pelo pro bono.

Nesse quadro, cada colaborador de uma law firm que completa suas 30 horas recebe uma insígnia Pro Bono Challenge. Tal evolução repousa, como já observamos, sobre uma cobrança por hora. Também revela, por outro lado, as mutaçóes conhecidas para uma profissão que, nos seus primórdios, não cobrava honorários - na Inglaterra, os barristers tinham com sua toga uma pequena bolsa que eles passavam e na qual as pessoas que defendiam eram livres de depositar ou não uma moeda. No início da informatizaçáo da cobrança um antigo advogado da ordem de Versailles, André Damien declarava entusiasmado que o honorário calculado pelo computador segundo o serviço fornecido, será "fixo, estável e preciso como a nota de um grande hotel” (apud ASSIER-ANDRIEU, 2011, p. 103).

\section{A escolha dos destinatários: entre a busca de um consenso humanitário e militância de consciência tranquila}

No seu acórdão Lassiter versus Department of Social Services (junho 1981), a Corte Suprema dos Estados Unidos decidiu que o direito à assistência judiciária reconhecido pela jurisprudência Gideon versus Wainwright valia apenas para o domínio penal, e não se aplicava nas questôes cíveis. Abriu-se dessa forma um campo para as práticas não mercantis do direito, espaço que era contemporâneo da integração, na Europa, dos práticos nas lógicas de mercado. Em seu artigo que sintetiza o estado da arte sobre a questão, Scott Cummings e Rebecca Sandefur apontam que há um conjunto de elementos que merecem maior esclarecimento. Entre estes, figuram as maneiras como as firmas escolhem seus temas de pro bono e incluem as causas na agenda (CUMMINGS e SANDEFUR, 2013, p. 99).

Para poder abordar essa questão, é primordial compreender que o sentido que os Estados Unidos aportam na forma de law firms é uma institucionalização do pro bono. Já existem manuais de pro bono e, nos escritórios de advocacia o modelo mais de ponta sobre o assunto, remete à institucionalização do pro bono. A política geral nesse domínio é determinada por uma pessoa inteiramente dedicada a esta questão e chamada de pro bono partner. Aquele que pode se apoiar sobre pontos regionais, chamados de regional pro bono managers, na Europa, no Reino Unido, na África, na Ásia e na Austrália, os quais tem sob sua responsabilidade os pro bono cordinators. A cada quatro anos o pro bono partner, em colaboração com o Board de DLA Piper, escolhe três a quatro temas. Nesse momento, os direitos das pessoas deslocadas, os 
direitos da infância e a promoção do rule of law, que são, em seguida, impostos a todos os colaboradores. Estes náo podem atuar em qualquer causa pro bono. Trata-se de trabalhar para as associaçóes conhecidas e reconhecidas (raramente para indivíduos) e há matérias que não são muito escolhidas. No caso da sociedade Morgan Lewis, os funcionários junior, middle ou sênior, assim como os counsels, podem iniciar um pro bono, mas sua proposta é estreitamente enquadrada e vinculada a sede nos Estados Unidos.

\section{Apelo ao público e promoção da agenda dos lawyers}

Para compreender como ocorre a escolha dos destinatários dos programas pro bono, formulo a hipótese segundo a qual o "público" a quem se destinam essas atividades é uma ficção silenciosa, mas bem fundada que os lawyers definem e dão voz $^{3}$ para implementar sua própria agenda. Esta hipótese é um prolongamento de um dos resultados de minha tese de doutorado sobre a sociogênese da idéia de serviço público na França. Nesse sentido tento demonstrar que a noção de "público" invocada na alta função pública pelos legisladores e pelos sindicatos, designa menos o povo, do que uma construção imaginária destinada a assegurar uma forma relativamente inquestionável de legitimidade em um campo onde as açôes de interesse geral são reconhecidas e valorizadas ${ }^{4}$. Esta problemática aproxima a prática do pro bono tal como é construída pelos escritórios de advocacia do fenômeno de fabricação da opinião pública pelas sondagens, tal como mostram os estudos de Blondiaux (1998) e Champagne (1990). Assim como o mecenato de talentos é indicativo de qualidade, o pro bono não se apresenta como pura caridade, e "não há hoje em dia filantropia desinteressada” (DANIELS e MARTIN, 2009, p. 154).

Podemos pensar que o mercado pro bono não é determinado pela demanda do público, mas pelos interesses e prioridades daqueles que aportam recursos. Em outros termos, parece que com o pro bono são as law firms que implementam sua própria agenda e suas próprias causas. Para não ficar em uma mera hipótese de denúncia, é preciso observar que o pro bono não serve apenas como caridade dos

\footnotetext{
${ }^{3}$ Aqui, pode ser útil lembrar a etimologia da palavra "advogado", ou seja, o ad-vocatus, "quem é chamado para falar".

${ }^{4}$ Esses elementos são desenvolvidos por Pierre Bourdieu na conferência "Espíritos de Estado: gênese e estrutura do campo burocrático", bem como no curso do Collège de France. "É possível um ato desinteressado?", dois textos reproduzidos em Razões Práticas (BOURDIEU, 1994), respectivamente.
} 
advogados que o praticam: sua função é também, para os escritórios, um meio de se tornarem mais atrativos para os clientes e potenciais novos recrutados e associados. Se o pro bono é um mercado de causas que se desenvolve sob o modo de um edital e uma concessão, isso significa que a competição ocorre dos dois lados (entre os fornecedores, assim como entre os beneficiários). Rebecca Sandefur revela que no caso americano é nos estados onde os juristas sofrem mais com a competição, que a taxa de pro bono é mais elevada (SANDEFUR, 2007, p. 93). A partir do momento em que o pro bono é uma maneira de destacar os escritórios de advocacia, como os escritórios de assistência judiciária servem, em alguma medida, para as grandes universidades, podemos nos questionar, como faz Catherine Raguin no momento em que é introduzida a assistência judiciária na França, se nessas condições, a justiça para os pobres não se limita a uma "justiça barata” (RAGUIN, 1972, p. 166).

\section{Mediadores a serviço de causas?}

No domínio do pro bono raramente os escritórios de advocacia se dirigem diretamente às ONGs ou associaçôes e vice-versa. Ambos passam por intermediários chamados de clearing houses. Cada parte do mundo onde o pro bono é desenvolvido conta com uma ou mais dessas estruturas: nos Estados Unidos, Pro Bono Institute e a American Pro Bono Counsel Association; na Europa, Pilnet e Public Interest Network; na Austrália, Justice Connect; na Asia, Babseacle. Essas clearing houses organizam cada ano o Pro Bono Fórum grande rede que reúne o conjunto dos atores do setor, os quais não se limitam aos escritórios de advocacia. Nesse ambiente encontram-se universitários, ONGs, organizaçóes internacionais, representantes dos Estados em desenvolvimento e dos empresários da economia social e solidária. Por meio de uma adesão implicando uma cotização anual, esses intermediários aparecem incontornáveis, conforme observa um entrevistado:

o dia em que aderimos a uma clearing house, isso realmente impulsionou nossa atividade. Nós contratamos um managing partner e, em seguida criamos várias antenas pro bono. Hoje não podemos fazer nada sem ela. Nossa responsável pro bono na Europa é desde então contratada também por Pilnet (entrevista n. 5, pro bono director, mulher, 44 anos). 
O serviço fornecido no quadro desta relação tem globalmente pouco a ver com a representação jurisdicional. Trata-se antes de consultoria em engenharia jurídica. Um prático especializado em private equity explica assim:

eu trabalho muito com a África. Quando eu viajo, tenho sempre um volet pro bono. Por exemplo, Anistia Internacional quer abrir uma antena em um país da África. Eu lhes forneço um pacote contratual lhes garantindo segurança da transaçáo e explicando todos os detalhes jurídicos que eles precisam observar. De certa forma eu lhes entrego o projeto pronto (entrevistado número 4, sócio, homem, 61 anos).

Em outros termos, as multinacionais do Direito se impõem como atores inevitáveis da mediação filantrópica que sustenta os estados que encontram localmente sérias dificuldades para garantir o acesso à justiça aos mais pobres. Como afirma o economista Susan Strange:

as sociedades transnacionais (STN) jogam um papel significativo na determinação do 'quem obtém o quề no sistema mundial (...) porque ao longo da última década, as STN têm contribuído mais que os estados e as organizaçóes internacionais de ajuda na redistribuição da riqueza dos países industriais desenvolvidos para os países em desenvolvimento (STRANGE apud MULLER, 2015, p. 190).

Esta evolução para uma ação pública desinteressada inteiramente nas mãos da empresa não ocorre sem conflitos de interesse. David Wilkins, especialista em profissões jurídicas da Harvard Law School, realiza um balanço quanto à independência dos escritórios de advocacia empresarial retratando sua sujeição crescente a uma clientela de corporações capazes de impor suas próprias regras de funcionamento, e mesmo burlar as regras deontológicas, "o hemisfério mais prestigiado da prática jurídica é, ao mesmo tempo, o menos independente" (WILKINS, 1992, p. 867).

$\mathrm{Na}$ medida em que ela implica uma colaboração com as law firms e, em algumas vezes, com seus clientes, a prática do pro bono não pode ser descrita como neutra do ponto de vista das ONGs e associações. Estas podem defender causas que os responsáveis posicionados na elite de uma parceria podem achar muito controversas, como ocorreu há alguns anos nos Estados Unidos com uma clínica de 
direito que auxiliava indivíduos a atacar uma companhia petrolífera após uma maré negra no golfo da Louisiana ${ }^{5}$. O risco de conflito de interesse tem por resultado uma fraca politização na escolha dos destinatários que são apoiados ${ }^{6}$. Aqui há, contudo, uma diferença a considerar entre as práticas em curso na França e nos Estados Unidos. Neste último país, os advogados se engajam em processos defendendo os prisioneiros de Guantánamo ou contra a pena de morte. Isso se explica em parte pela relativa falta de acesso à assistência judiciária nos Estados Unidos e pela politização da vida judiciária americana devida à eleição de juízes e procuradores em diversos estados americanos. Assim, os processos com assuntos sensíveis tais como a eutanásia seriam descartados no caso do pro bono dos escritórios de advocacia empresarial franceses, em proveito de causas moralmente mais neutras, como o acesso à justiça, a ajuda aos pobres e às crianças.

Do ponto de vista dos colaboradores, que, conforme observamos, não podem escolher a quem vão ofertar seu serviço quatro vezes sobre cinco, a participação nos projetos pro bono do escritório é imposta. Minha informante no interior do escritório, Morgan Lewis, indicou que o pro bono ocupava cada vez mais espaço na sua atividade: em 2015, o objetivo de cada funcionário era de completar 20 horas por ano; em 2016 o objetivo cresceu para 50 horas. O pro bono deve assim tornar-se uma rotina e, a esse título, deve ser gerido como qualquer outro processo, mesmo que seja esclarecido aos funcionários que o trabalho com os clientes "que pagam" deve ser priorizado. Eles se encontram, dessa forma, em uma situação dúbia, empenhados para satisfazer os clientes que os remuneram (indiretamente) e, ao mesmo tempo, dedicando-se às horas pro bono necessárias para o prestígio simbólico da profissão e, acessoriamente, da sua consciência:

posso dizer que $95 \%$ do meu trabalho e do meu tempo mental é dedicado a fusão-aquisição para os grandes grupos. Veja, o tipo de processos onde não há sentimentalismo. Então eu te digo que tenho a impressão de sujar minhas mãos, mas eu sou cristã, então eu te diria que pegar um processo pro bono aqui e acolá, me faz bem. Tenho a impressão de reparar o mal que eu faço a maior parte do tempo (entrevistada n. 2, junior associate, mulher, 27 anos).

\footnotetext{
${ }^{5}$ Sobre esta questão, ver Babich (2011).

${ }^{6}$ Como afirmou um entrevistado "nós não queremos mudar o mundo, nós queremos apenas ajudar" (entrevista némero 5, pro bono director, mulher, 44 anos).
} 


\section{Conclusão}

Pesquisar sobre o pro bono implica uma tentativa de analisar o fenômeno do transplante jurídico do mundo do mercado globalizado e traz como questão central o questionamento das fronteiras nacionais desse tipo de prática jurídica. Quando uma law firm americana típica abre uma filial em Paris e reivindica práticas da "virtude" pro bono, a bandeira nacional tem alguma importância? A resposta a esta questão é incerta. É arriscado supor que a definição de pro bono não é objeto de lutas nos Estados Unidos, em um país que é o berço dessa prática a fortiori em um momento onde a forma organizacional que o desenvolveu - a law firm - se acha contestada. Do ponto de vista "francês", não há nenhuma dúvida que quando os americanos apostam em alguma coisa, isso faz uma enorme diferença em termos de volume de recursos investidos.

$\mathrm{O}$ que se pode observar na França é que ainda não ocorre uma institucionalização do pro bono, como chamamos a atenção no início. A maioria dos advogados trabalham em estruturas médias (20 a 50 assalariados) e pequenas (menos de 10), as quais se reduzem às vezes a um simples compartilhamento de estrutura (uma impressora em comum), de forma que a comparaçáo se torna difícil em relação às multinacionais do direito. $\mathrm{O}$ exemplo americano mostra bem que quanto mais elevado o volume de negócios de um escritório, mais ele fará o pro bono. Esta é uma condição para que este último funcione como um dispositivo de ação pública, ou seja, como um meio de impulsionar a riqueza e de distribuí-la sem passar pelo Estado. Nesse sentido, o pro bono aparece como uma forma das empresas ajudarem os ricos e os pobres. É nessa exata medida que os profissionais do campo jurídico podem continuar a se situar ao lado do que os sociólogos dos movimentos sociais chama de "helping professions" (MCADAM, 1989, p. 746), no caso das law firms, elas se alinharam ao lado de um capitalismo financeiro pouco inclinado a destinar dinheiro ao Estado Social.

Charles Bosvieux-Onyekwelu é Doutor em Ciências Sociais, Pós Doutorando na École des Hautés Études em Sciences Sociales. Email: charles.bosvieux-onyekwelu@normalesup.org. 


\section{Referências}

ASSIER-ANDRIEU, Louis. Les avocats: identité, culture et devenir. Paris: Lextenso, 2011.

AVRIL, Christelle; CARTIER, Marie e SERRE Delphine. Enquêter sur le travail concepts, méthodes, récits. Paris: La Découverte, 2010.

BABICH, Adam. Controversy, Conflicts and Law School Clinics. Clinical Law Review, v. 17, n. 2, p. 469-513, 2011.

BESSY, Christian. L'organisation des activités des avocats: entre monopole et marché. Paris: LGDJ, 2015.

BLONDIAUX, Loïc. La fabrique de l'opinion: une histoire sociale des sondages, Paris, Éditions du Seuil, 1998.

BOIGEOL, Anne. De l'idéologie du désintéressement chez les avocats. Sociologie du travail, v. 23, n. 1, p. 78-8, 1981.

BONICHOT, Jean-Claude; MORAND-DEVILLER Jacqueline. Mondialisation et globalisation des concepts juridiques: l'exemple du droit de l'environnement. Paris: IRJS Éditions, 2010.

BOURDIEU, Pierre. Raisons pratiques: sur la théorie de l'action. Paris: Éditions du Seuil, 1994.

CHAMPAGNE, Patrick. Faire l'opinion: le nouveau jeu politique. Paris: Éditions de Minuit, 1990.

COLLOVALD, Annie; LECHIEN, Marie-Hélène; ROZIER, Sabine; WILLEMEZ Laurent. L'humanitaire ou le management des dévouements: enquête sur un militantisme de solidarité internationale en faveur du Tiers-monde. Rennes: Presses Universitaires de Rennes, 2002.

CUMMINGS, Scott. The Politics of Pro Bono. In: KAUFMAN, Andrew; WILKINS David (Orgs.). Problems in Professional Responsibility for a Changing Profession, Durham: North Carolina Press, 2009, p. 303-452.

CUMMINGS, Scott; SANDEFUR, Rebecca. Beyond the Numbers: What We Know - and Should Know - about American Pro Bono. Harvard Law and Policy Review, v. 83, n. 7, p. 83-111, 2013.

DANIELS, Stephen; MARTIN, Joanne. Legal Services for the Poor: Access, Self-Interest and Pro Bono. In: SANDEFUR, Rebecca (Org.). Access to Justice: Sociology of Law, Crime and Deviance. Chicago: Emerald Group Publishing Limited, 2009, p. 145-166.

DEZALAY, Yves. Marchands de Droit: la restructuration de l'ordre juridique international par les multinationales du Droit. Paris: Fayard, 1992.

Les usages internationaux du concept de champ juridique. Actes de la recherche en sciences sociales, v. 5, n. 200, p. 56-69 2013.

Enquêter sur l'internationalisation des noblesses d'État: retour réflexif sur des stratégies de double jeu. Cultures et conflits, n. 98, p. 15-52, 2015.

DEZALAY, Yves; GARTH, Bryant. The Confrontation between the Big Five and the Big Law: Turf Battle and Ethical Debates as Contests for Professional Credibility. Law and Social Inquiry, v. 29, n. 3, p. 615-638, 2004.

DIENER, Lilly. Avocats des droits de l'homme: la pratique du pro bono en France. Les cahiers de la justice, n. 1, p. 139-1154, 2016.

FRANCE, Pierre; VAUCHEZ, Antoine. Sphère publique, intérêts privés. Paris: Presses de Sciences Po, 2017.

GAUDEMET, Jean. Les transferts de droit. L'Année sociologique, n. 27, p. 29-59, 1996. 
GORDON, Robert. The Ideal and the Actual in the Law: Fantasies and Practices of New York City Lawyers. In: GAWALT, Gerard (Org.). The New High Priests: Lawyers in Post Civil War America. Westport: Greenwood Press, 1994, p. 51-74.

HASSENTEUFEL, Patrick. Sociologie politique: action publique. Paris: Armand Colin, 2011.

ISRAËL, Liora. L'arme du droit. Paris: Presses de Sciences Po, 2009.

JASANOFF, Sheila. Ce que sait le droit: la science au service de la décision de justice. In: JASANOFF, Sheila (Org.). Le droit et la science en action. Paris: Dalloz, 2013, p. 181-204.

JOY, Peter. The Law School Clinic as a Model Ethical Law Office, William Mitchell Law Review. v. 30, n. 1, p. 35-50, 2003.

KARPIK, Lucien. Les avocats: entre l'État, le public et le marché (XIIIe-XXe siècle), Paris, Gallimard, 1995.

LAMBELET, Alexandre. La philanthropie. Paris: Presses de Sciences Po, 2014.

McADAM, Doug. The Biographical Consequences of Activism. American Sociological Review, v. 54, n. 5, p. 744-760, 1989.

McCANN, Michael. Law and Social Movements In: SARAT Austin (Org.). The Blackwell Companion to Law and Society. Malden: Blackwell Publishing, 2004, p. 506-522.

MULLER, Pierre. La société de l'efficacité globale: comment les sociétés modernes se pensent et agissent sur elles-mêmes. Paris: PUF, 2015.

RAGUIN, Catherine. L'indépendance de l'avocat. Réflexion sur deux réformes: la rénovation de la profession et l'aide judiciaire. Sociologie du travail, v. 14, n. 2, p. 164-184, 1972.

SALAIS, Robert. La donnée n'est pas un donné: pour une analyse critique de l'évaluation chiffrée de la performance. Revue française d'administration publique, v 3, n.135, p. 497-515, 2010.

SANDEFUR, Rebecca. Lawyers' Pro Bono Service and American-Style Civil Legal Assistance. Law and Society Review, v. 41, n. 1, p. 79-112, 2007.

SARAT, Austin; SCHEINGOLD, Stuart. Cause Lawyering: Political Comments and Professional Responsibilities. Oxford: Oxford University Press, 1998.

. Something to Believe in: Politics, Professionalism and Cause Lawyers. Stanford: Stanford University Press, 2004.

. Cause Lawyers and Social Movements, Stanford: Stanford University Press, 2006.

SAUTÉ Robert. For the Poor and Disenfranchised: an Institutional and Historical Analysis of American Public Interest Law (1876-1990), Ann Arbor: ProQuest, 2008.

SAVAS, Emanuel S. Privatization and the New Public Management. Fordham Urban Law Journal, v. 28, n. 5, p. 1731-1738, 2000.

SILVER, Carole. The Variable Value of US Legal Education in the Global Legal Services Market. Georgetown Journal of Legal Ethics, v. 24, n. 1, p. 1-57, 2011.

SIMÉANT, Johanna. Face à l'international: textes et pratiques de l'enquête en sciences sociales. In: SIMÉANT, Johanna (Org.). Guide de l'enquête globale en sciences sociales. Paris: CNRS, 2015, p. 5-11.

VAUCHEZ, Antoine. L'avocat d'affaires: un professionnel de la classe dirigeante. Savoir/agir, v. $01 \mathrm{n}$. 19, p. 39-47, 2012.

WATSON, Alan. Legal Transplants: an Approach to Comparative Law. Édimbourg: Scottish Academic Press, 1974. 
52 | Charles Bosvieux-Onyekwelu

WILKINS, David. Who Should Regulate Lawyers? Harvard Law Review, v. 105, n. 4, p. 799-887, 1992.

WILLEMEZ, Laurent. De l'expertise à l'enchantement du dévouement. In: COLLOVALD, Annie; LECHIEN, Marie-Hélène; ROZIER, Sabine; WILLEMEZ Laurent (Orgs.). L'humanitaire ou le management des dévouements: enquête sur un militantisme de solidarité internationale en faveur du Tiers-monde. Rennes: Presses universitaires de Rennes, 2002, p. 48-72.

Texto recebido em 13 de agosto de 2018. Aprovado em 22 de outubro de 2018. 